\title{
Damage and Fracture Behaviours in Aged Austentic Materials During High-Temperature Slow Strain Rate Testing
}

\author{
Mattias Calmunger, Guocai Chai, Sten Johansson and Johan Moverare
}

\section{Linköping University Post Print}

\section{Tweet}

N.B.: When citing this work, cite the original article.

Original Publication:

Mattias Calmunger, Guocai Chai, Sten Johansson and Johan Moverare, Damage and Fracture Behaviours in Aged Austentic Materials During High-Temperature Slow Strain Rate Testing, 2014, Key Engineering Materials, (592-593), 590-593.

http://dx.doi.org/10.4028/www.scientific.net/KEM.592-593.590

Copyright: Trans Tech Publications http://www.ttp.net/

Postprint available at: Linköping University Electronic Press http://urn.kb.se/resolve?urn=urn:nbn:se:liu:diva-96028 


\title{
Damage and fracture behaviours in aged austenitic materials during high-temperature slow strain rate testing

\author{
Mattias Calmunger ${ }^{1, a}$, Guocai Chai ${ }^{1,2, b}$, Sten Johansson ${ }^{1, c}$ and Johan \\ Moverare $^{1, d}$
}

\author{
${ }^{1}$ Division of Engineering Materials, Department of Management and Engineering, Linköping \\ University, SE-58183 Linköping, Sweden
${ }^{2}$ AB Sandvik Materials Technology R\&D center, SE-81181 Sandviken, Sweden

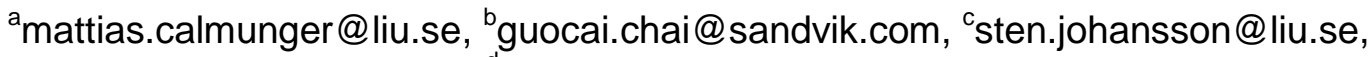 djohan.moverare@liu.se

\begin{abstract}
Keywords: High-temperature, ageing, slow strain rate, biomass power plant, austenitic stainless steel, nickel base alloy and dynamic strain ageing.

Abstract. Biomass power plants with high efficiency are desired as a renewable energy resource. High efficiency can be obtained by increasing temperature and pressure. An upgrade of the material performance to high temperature material is therefore required in order to meet the increased demands due to the higher temperature and the more corrosive environment. In this study, the material's high-temperature behaviours of AISI 304 and Alloy617 under slow deformation rate are evaluated using high-temperature long-term aged specimens subjected to slow strain rate tensile testing (SSRT) with strain rates down to $10^{-6} / \mathrm{s}$ at $700^{\circ} \mathrm{C}$. Both materials show decreasing stress levels and elongation to fracture when tensile deformed using low strain rate and elevated temperature. At high-temperature and low strain rates cracking in grain boundaries due to larger precipitates formed during deformation is the most common fracture mechanism.
\end{abstract}

\section{Introduction}

Biomass power plants are referred as sustainable energy production and can get higher efficiency using higher temperature and pressure, which is preferred. Today many austenitic stainless steels and nickel base alloys are used as structural materials in biomass power plants and they need to have good long term mechanical properties with respect to the higher temperature and pressure [1].

Dynamic strain ageing (DSA) in austenitic materials can usually occur at the operating temperature range of biomass power plants [2] and arises during plastic deformation from interaction between solute atoms and mobile dislocations [3]. DSA is characterized by serrated yielding [4].

This study was focused on damage and fracture mechanisms of high-temperature long term aged austenitic materials during uniaxial slow strain rate tensile testing (SSRT) at room temperature and high-temperature. The role of precipitation from high-temperature ageing and deformation is evaluated and coupled to the damage and fracture behaviour.

\section{Materials and Experimental}

The experiments were conducted on one austenitic stainless steel (AISI 304) and one nickel base alloy (Alloy 617), supplied by Sandvik Materials Technology, see Table 1 for nominal compositions. The materials are solution heat treated.

Table 1. Compositions for the different materials in [wt\%].

\begin{tabular}{cccccccccccccc}
\hline Material & $\mathrm{C}$ & $\mathrm{Si}$ & $\mathrm{Mn}$ & $\mathrm{Cr}$ & $\mathrm{Ni}$ & $\mathrm{W}$ & $\mathrm{Co}$ & $\mathrm{Cu}$ & $\mathrm{N}$ & $\mathrm{Mo}$ & $\mathrm{Ti}$ & $\mathrm{Nb}$ & $\mathrm{Fe}$ \\
\hline AISI 304 & 0.015 & 0.35 & 1.2 & 18.3 & 10.3 & 0.05 & - & 0.3 & 0.07 & 0.3 & - & 0.01 & Bal. \\
\hline Alloy 617 & 0.06 & 0.04 & 0.02 & 22.5 & 53.8 & 0.02 & 12 & 0.01 & - & 9 & 0.5 & 0.02 & 1.1 \\
\hline
\end{tabular}


Three cylindrical tensile test specimens (diameter $5 \mathrm{~mm}$ and measure length $50 \mathrm{~mm}$ ) of each alloy were prepared and then aged at $700^{\circ} \mathrm{C}$ for 500 hours in air, and the specimens were water quenched after the ageing. Uniaxial slow strain rate tensile testing (SSRT) was then done in a Instron 5982 electromechanical machine equipped with a Instron SF16 furnace and a Instron 7361C extensometer. Two temperatures, room temperature (RT) and $700^{\circ} \mathrm{C}$, were used, and two strain rates, $2 * 10^{-3} / \mathrm{s}$ and $10^{-6} / \mathrm{s}$, were used.

The Cross-section along the deformation axis of each sample were carefully ground and polished before the microstructure were investigated using electron channeling contrast imaging (ECCI) [5].

\section{Results and discussion}

Influence of precipitates on the tensile behavior. Engineering stress-strain curves from the SSRT (Fig.1) show that Alloy 617 has better tensile mechanical properties compared with AISI 304 at both RT and $700^{\circ} \mathrm{C}$ under aged conditions. At RT compared to non-aged [6] the two materials have undergone hardening due to the precipitates formed during the ageing process. Alloy 617 has intragranular small evenly distributed $\gamma^{\prime}$ precipitates that give the most of the hardening effect at RT, see Fig. 2 a). AISI 304 shows mostly intergranular precipitates, probably some kind of Cr-rich carbide, these precipitates seem to be the reason for the hardening at RT, see Fig.3 a). As expected, at elevated temperature the stress levels were much lower than at RT and when using a strain rate of $10^{-6} / \mathrm{s}$ they show a softening effect during the plastic deformation probably affected by supposed dynamic recrystallized (DRX) structure at the grain boundaries (GBs). DRX makes the material more ductile but appears only in the GBs. The elongation to fracture is decreasing with increasing temperature when using a strain rate of $10^{-6} / \mathrm{s}$ for both materials, both intra- and intergranular precipitates affect this behaviour and at high-temperature SSRT DRX have a contributing effect.

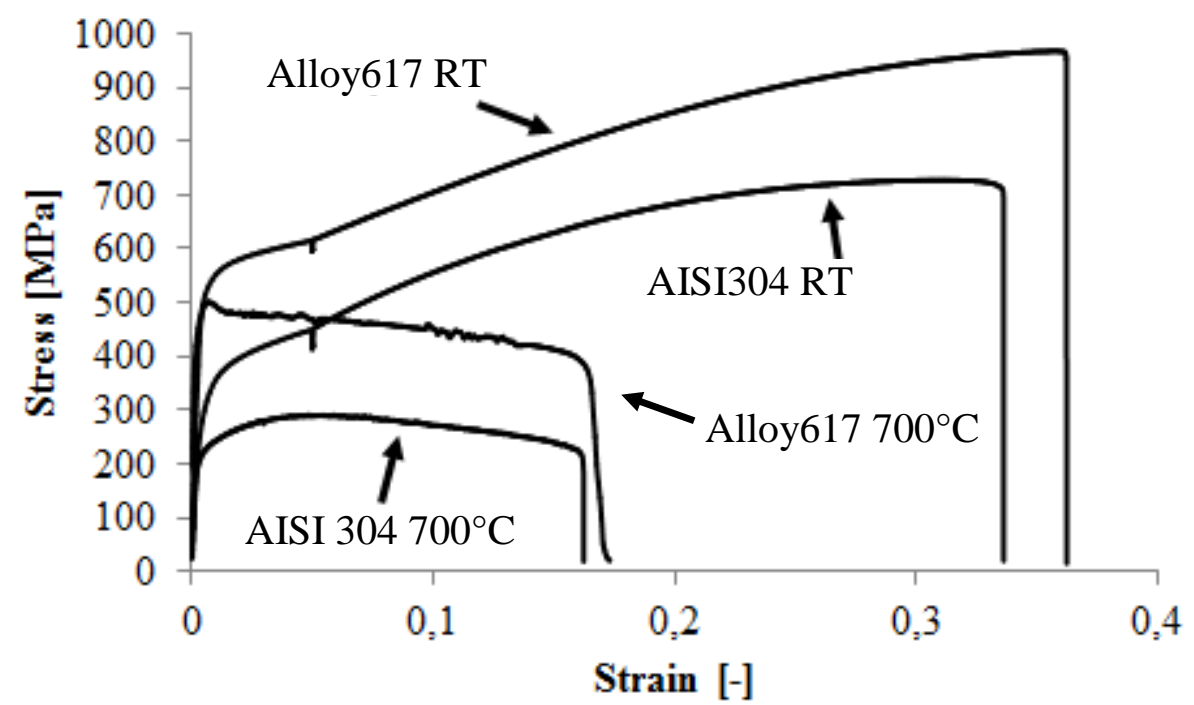

Figure 1. Engineering stress-strain curves show AISI 304 and Alloy 617 aged and SSRT.

The strain rate influences the fracture surface appearances; with a low strain rate the fracture surface is perpendicular to the loading direction and using a higher strain rate gives a fracture surface around $45^{\circ}$ to the loading direction. AISI 304 shows a mixture of these appearances when fractured using a strain rate of $10^{-6} / \mathrm{s}$ at $700^{\circ} \mathrm{C}$.

At the low strain rate and elevated temperature DSA occurred for these alloys. The precipitates from the ageing process seem to decrease the intensity of serrated yielding. AISI 304 shows less serrated yielding at the low strain rate at $700^{\circ} \mathrm{C}$ than for a higher straining rate. For aged samples of Alloy 617 serrated yielding is not present at $700^{\circ} \mathrm{C}$ using a strain rate of $2 * 10^{-3} / \mathrm{s}$, but DSA occur in the stress-strain curve for the non-aged sample under same conditions [7]. However, the serrated yielding occurs when using a strain rate of $10^{-6} / \mathrm{s}$ at $700^{\circ} \mathrm{C}$, probably due to a decrease in dislocation motion rate. However, the decrease of DSA could be due to precipitates acting barriers that decrease the free path of the dislocations motions [8]. The evenly distributed small $\gamma^{\prime}$ precipitates 
(Fig.2 b)) in Alloy 617, seems to be more effective barriers than the precipitates that occur in the AISI 304 stainless steel.

Influence of precipitates on damage and fracture. There are differences between the strain rates regarding precipitation, both AISI 304 and Alloy 617 using a strain rate of $10^{-6} / \mathrm{s}$ at $700^{\circ} \mathrm{C}$ shows more and larger intergranular precipitates and a possible DRX structure. This means that the larger intergranular precipitates is formed during SSRT at elevated temperature and can be due to a combination of the longer deformation time at elevated temperature and the presences of dislocations junctions, possibly assisted by pinning of dislocations from the DSA process, that simplify the nucleation of precipitates in GB [9]. The intergranular precipitates cause GB embrittlement when $\mathrm{Cr}$ and $\mathrm{C}$ atoms diffuse to the GB to form carbides that often cracks between GB and the precipitate. The supposed DRX structures in the GBs in front of cracks can also contribute to the intergranular fracture by assisting precipitate nucleation which acting crack initiation spots, and interaction between slip bands and DRX in GB that also leads to crack initiation, and DRX softening the GB during plastic deformation that easier the crack propagation, see Fig.4. At even higher temperatures (around $1000^{\circ} \mathrm{C}$ ) DRX can causes GB sliding [10]. For Alloy 617 at RT using a low strain rate, small precipitates in the GBs formed during the ageing process, causes voids and cracks when they interact with slip bands that finally lead to intergranular fracture, see Fig.2 a). AISI 304 form larger and elongated precipitates in the GBs than the nickel base alloy, during the ageing process, which assists crack initiation and propagation displayed in Fig.3. Both materials show primary precipitates formed during the manufacturing process that either crack themselves or causes cracking between the precipitate and the matrix or GB, see Fig.3. In all figures the loading direction is upwards in the picture, the pictures are performed using ECCI.

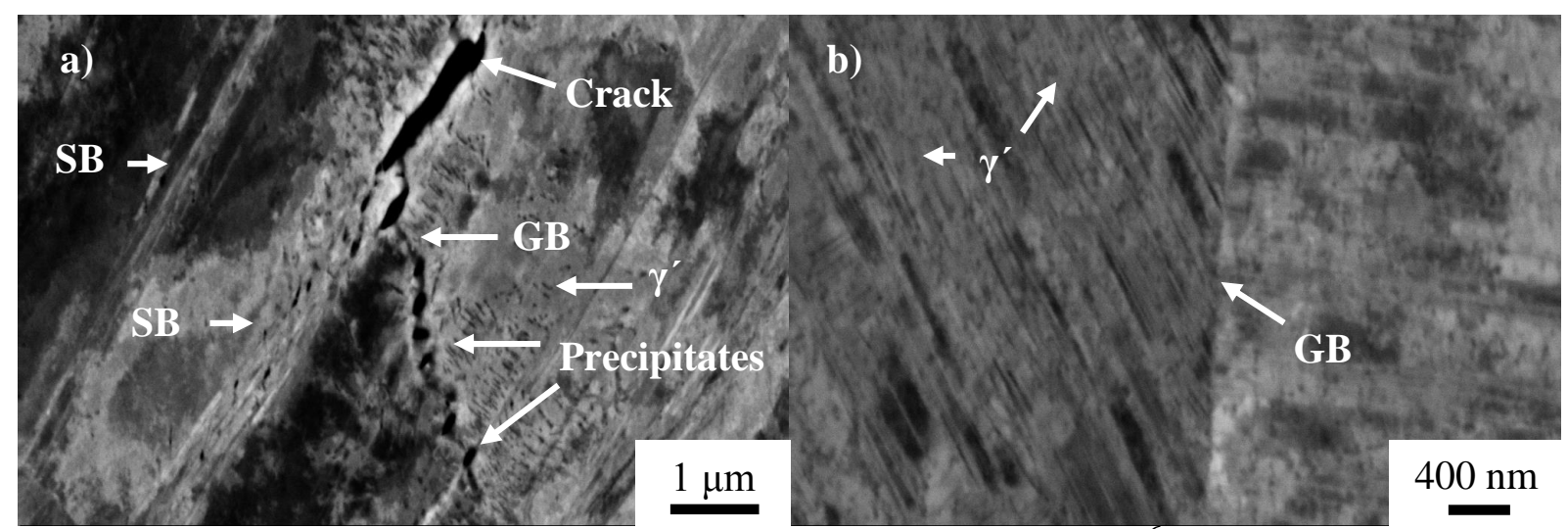

Figure 2. Alloy 617 tensile tested a) at RT and using a strain rate of $10^{-6} / \mathrm{s}$, displaying crack formed by interaction between slip band and small precipitates in GB and b) show evenly distributed $\gamma^{\prime}$ precipitates in the grains when tested using a strain rate of $2 * 10^{-3} / \mathrm{s}$ at $700^{\circ} \mathrm{C}$.

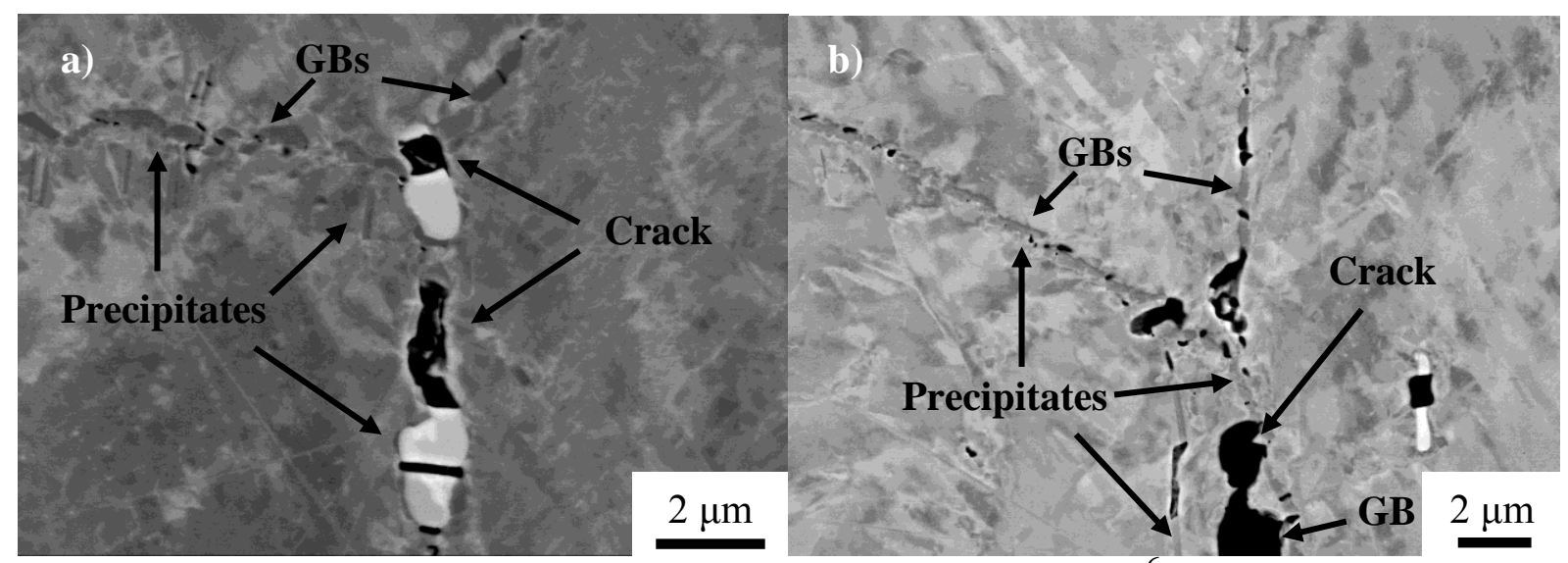

Figure 3. AISI 304 tensile tested a) at RT and using a strain rate of $10^{-6} / \mathrm{s}$, displaying cracks in GB due to stress concentrations formed by precipitates, both primary and from the ageing process and b) show a crack propagated in the GB due to stress concentrations formed by precipitates when tested using a strain rate of $2 * 10^{-3} / \mathrm{s}$ at $700^{\circ} \mathrm{C}$. 


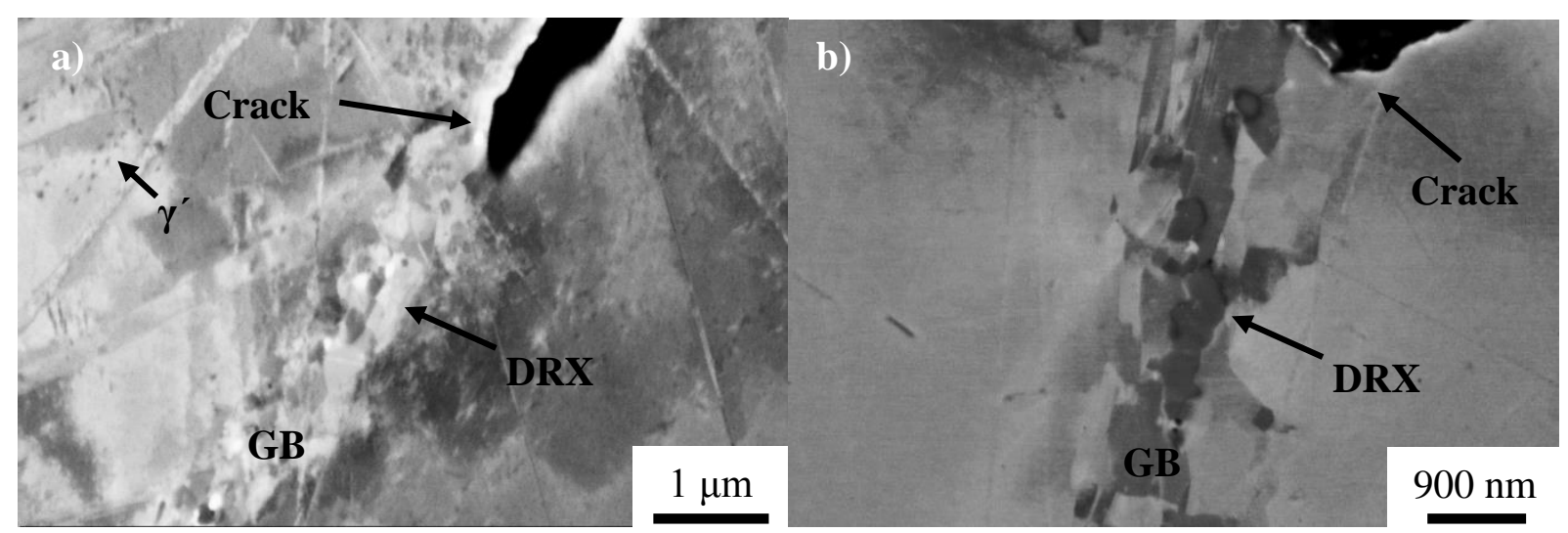

Figure 4. a) Alloy 617 respectively b) AISI 304 tensile tested at $700^{\circ} \mathrm{C}$ and using a strain rate of $10^{-}$ $\%$ s, both material display structures looking like dynamic recrystallization (DRX).

\section{Conclusion}

Slow strain rate tensile testing caused intergranular fracture in both high-temperature long term aged AISI 304 and Alloy 617 at both RT and $700^{\circ} \mathrm{C}$ when using a strain rate of $10^{-6} / \mathrm{s}$. At RT the fracture is caused by cracks initiated due to stress concentration formed by the precipitates from the ageing process in the GBs for both alloys. Alloy 617 also exhibit crack initiation and propagation by slip band interaction with the small GB precipitates. At $700^{\circ} \mathrm{C}$ the fracture is caused by larger GB precipitates formed during the tensile deformation. Elongation to fracture decreases for both the aged stainless steel and the aged nickel base alloy when a lower strain rate is used compared with a higher strain rate at $700^{\circ} \mathrm{C}$. The ageing process gives a hardening effect for both alloys and the tensile strength decrease with increasing temperature.

\section{Acknowledgements}

Present study was financially supported by AB Sandvik Materials Technology in Sweden and the Swedish National Energy Administration through the Research Consortium of Materials Technology for Thermal Energy Processes, Grant No. KME-501. Agora Materiae and Strategic Faculty Grant AFM at Linköping University is also acknowledged.

\section{References}

[1] J. Pettersson, H. Asteman, J. Svensson, L. Johansson: Oxidation of Metals Vol. 64 (2005), p. 23

[2] L.H. de Almeida, I. Le May, P.R.O. Emygdio: Mater Charact. Vol. 41 (1998), p. 137

[3] M.A. Soare, W.A. Curtin: Acta Materialia Vol. 56 (2008), p. 4046

[4] P. Rodriguez: Bulletin of Materials Science Vol. 6 (1984), p. 653

[5] I. Gutierrez-Urrutia, S. Zaefferer, D. Raabe: Scr. Mater. Vol. 61 (2009), p. 737

[6] M. Calmunger, G. Chai, S. Johansson, J. Moverare: ICF13 (2013), S22-004

[7] M. Calmunger: LIU-IEI-TEK-A-11/01236-SE (2011)

[8] S. Liang, Z. Qing-Chuan, C. Peng-Tao: Chinese Physics B Vol. 18 (2009), p. 3500

[9] M. Hörnqvist, B. Karlsson: Procedia Engineering Vol. 2 (2010)

[10] B. Mintz, A. Cowley, R. Abushosha, D.N. Crowther: Materials Science and Technology Vol. 15 (1999), p. 1179 